\title{
Aflatoxinas B1 y su asociación con el cáncer de hígado
}

El cáncer hepatocelular es por excelencia el tumor en el cual podemos tener una intervención temprana y así prevenirlo.

Son varios los factores asociados con la aparición del cáncer hepatocelular, entre ellos: el alcohol, las hepatitis virales, la colangitis esclerosante, las drogas, las aflatoxinas, etc.

Los médicos podemos intervenir y prevenir dicha patología, mediante la educación a la colectividad respecto de los cambios en sus hábitos de vida (disminución de la ingesta de alcohol), conducta sexual segura y programas de vacunación masivos, (virus de la hepatitis B). Pero de gran relevancia en cuanto a prevención se refiere, es el papel de las aflatoxinas como agentes inductores del cáncer hepatocelular, y su vínculo con los granos de consumo cotidiano contaminados con el hongo Aspergillus flavus.

En 1990 la Revista Médica de Costa Rica publicó un artículo acerca de las aflatoxinas y el cáncer hepatocelular, en un estudio de casos y control en 15 grupos familiares y la relación con la ingesta de maíz y sus derivados. ${ }^{1}$ También se ha abordado una sumatoria de factores que propician el desarrollo de dicho cáncer, como son: haber padecido cirrosis, fibrosis hepática, o infección por virus la de hepatitis B. ${ }^{2}$. En este mismo contexto, la infección por virus de la he-patitis B y el consumo de granos contaminados con el hongo que produce las aflatoxinas, eleva dos veces el riesgo de desarrollar cáncer hepatocelular. ${ }^{3}$ Claro está, también se ha implicado la susceptibilidad genética, y ante la exposición reiterada de las aflatoxinas es posible desarrollar un cáncer hepatocelular, básicamente de la aflatoxina B1 ${ }^{4}$.

Además, se ha documentado que algunos alimentos que contienen soya, ácido ascórbico, alfa tocoferol, o retinol, tienen cualidades antimutagénicas en pruebas en células HepG2, con un requerimiento, para este fin, de 30 microgramos $/ \mathrm{ml}$, y protegen del efecto mutágeno de las aflatoxinas hasta en un $50 \%{ }^{5}$.

En el germen de trigo, en el maíz y en la fibra se han encontrado diferentes tipos de aflato-xinas en diversas concentraciones. Por ejemplo, se determinó que las aflatoxinas G1 y G2 son los tipos predominantes (cercanos al 80\%) y que las B1 y B2 son aproximadamente el $14 \%{ }^{6}$.

Cada vez es más necesario investigar el verdadero papel que desempeñan las aflatoxinas en los alimentos de consumo diario en nuestro país, lo mismo que el porcentaje de contaminación por dicho hongo, las condiciones ideales de almacenamiento de los granos, y los factores que contribuyen para tal contaminación.

Urge, precisamente, saber de nuestra realidad nacional, conocer estadísticas propias para poder formular argumentos sólidos y entonces emitir criterios y directrices.

\section{Dr. Henry Zamora-Barquero Gastroenterólogo}

\section{Referencias}

1. Nayak NC. Hepatocellular carcinoma a model of human cancer: clinico-pathological features, etiology and pathogenesis. Indian J. Pathol Microbiol. $2003 ; 46: 1-16$

2. Fonseca J, Sittenfeld A, Mora C, Martén A, Brenes F, Salom I. Contenido y consumo humano de aflatoxinas y cáncer hepatocelular en Costa Rica 1990; 47:510.
3. kew MC. Synergistic interaction between aflatoxin B1 and hepatitis B virus hepatocarcinogenesis. Liver Int.2003:105-9.

4. McGlynn Ka, Hunter K, LeVoyer T, Rousch J, Wise $\mathrm{P}$, Michielli RA et al. Susceptibility to aflatoxin B1related primary hepatocellular carcinoma in mice and Humans. Cancer Res. 2003 Aug. 4594-601

5. Jun HS, Kim SE, Sung MK. Protective effect of soy bean saponins and major antioxidants against aflatoxin B-1 induced mutagenicity and DNA-adduct formation. J Med Food. 2002 Winter; 5: 435-40.

6. Aly SE. Distribution of aflatoxins in product and by-products during glucose production from contamined corn. Nahrung 2002; 46:341-4. 